text would be of interest to experienced implant dentists wishing to offer a single session procedure with an immediately functional and aesthetic provisional restoration.

M. Devine

\section{BIOMECHANICS IN ORTHODONTICS: PRINCIPLES AND PRACTICE}

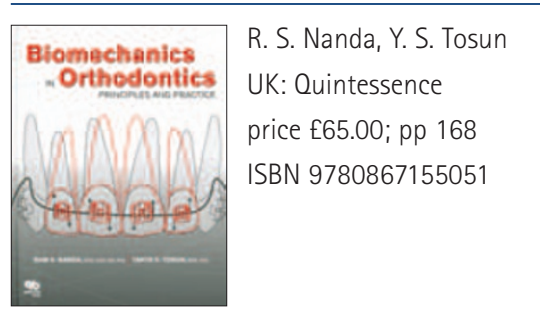

Biomechanics in orthodontics: principles and practice is a well-illustrated and comprehensive book that details the dental tissue responses and mechanical applications of orthodontic treatment to achieve successful outcomes. Its primary reading audience is postgraduate students and specialists who have an interest in the study of orthodontics.

This 168 page book is divided into nine chapters and follows two main sections. The first section is primarily non-clinical and provides the reader with a good understanding of the mechanical principles and its effects on isolated tooth movements. The second section details the orthodontic management of clinical cases and the application of these principles to provide an effective treatment plan.

The opening chapter entitled 'physical principles' starts by explaining the numerous laws of mechanics and forces applied in orthodontics. Readers may find this daunting when they first pick up the book given the use of terminology and concepts are primarily relevant to the study of physics. This issue, however, is clearly addressed by the authors who explain each principle systematically in clear and concise language and with good use of illustrations to allow straightforward understanding of advanced principles.

The book continues to detail the multifactorial component of biomechanics and its importance in orthodontics. This includes the material science and selection of wires, elastics and brackets, manipulating forces for long and short term and overall effect on dental tissues, to produce ideal tooth movements without harm.

Lastly, the authors outline the application of these rules in treating patients with differing orthodontic needs. Again, the systematic layout of this book allows the reader to easily digest the information provided by separating the chapters into the correction of vertical, transverse and anteroposterior discrepancies and finally space closure.

Throughout this book, the authors have used clear language to describe advanced principles which have been supplemented with good use of diagrams, graphical data and clinical photographs that makes reading the book straightforward and interesting. The authors have been logical in laying out chapters, helping the reader as one progresses through the book. Additionally, I have been impressed with the use of evidence-based practice where several studies and references have been used to help the practitioner make their own clinical decisions. Overall, this book would certainly be of great use to all those who have a special interest in the field of orthodontics.

R. S. Virdi

\section{CONTEMPORARY ESTHETIC DENTISTRY}

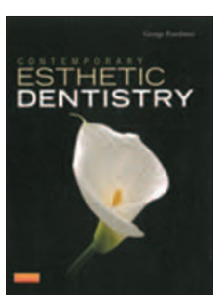

G. Freedman

UK: Elsevier

price €96.99; pp 832

ISBN 9780323068956

Contemporary esthetic dentistry is an all-encompassing detailed guide for the clinician aiming to achieve the highest possible aesthetic results. This hardback is aesthetically pleasing in itself with over 780 beautifully organised pages with striking, glossy colour photographs.

The text is divided up into manageable chapters which stream together logically, covering a broad spectrum of topics from cariology to adhesion and direct veneers to sterilisation and disinfection. Its layout is sensible and easy to read, with chapters sectioned into columns. There are over 57 contributors including cosmetic dentists, paedodontists and implantologists from all corners of the globe.

This book follows its title in describing modern techniques and methods to achieve aesthetically pleasing results, however, it expands and branches into much more. It offers the reader a complete and comprehensive insight into the work of aesthetic dentists who are at the top of their game.

The reader is guided through procedures from treatment planning to tooth preparation, laboratory process, adhesion and polishing. Each stage outlines how to improve on aesthetics through variables of materials, equipment and techniques. There are clinical photographs taken throughout the procedures and illustrations to help the reader to identify with the theory. The book contains case studies with impressive before and after clinical photographs showcasing new attractive smiles.

The reader can appreciate the artistic elements of dentistry with suggestions on how to integrate these harmoniously alongside treatment planning and clinical skill.

The text explores the fundamentals of aesthetic dentistry; giving an overview without becoming excessively detailed. The authors have kept the information very current by referring to trade names and showcasing various products. This is advantageous to clinicians wishing to emulate the procedures.

Freedman's book has broadened my horizons as to what types of materials are available and on the market, such as gingival coloured composite which would be indispensible when restoring Class V lesions.

I found the text very clinically relevant, especially the section on achieving contact points during Class II composite restorations. As a result of reading this book I have made adjustments to my clinical practice, with higher aesthetic results as an outcome.

In my opinion this is less of a reference book and more of an enjoyable read over a coffee to expand on one's knowledge base. It helps to re-affirm in the clinician's mind that one goal of tooth restoration is to improve on aesthetics.

L. MacAulay 